\title{
スプリンクラー消火設備による吸熱特性
}

\section{Endothermic Characteristics of Sprinkler extinction equipment}

○多田 直人（福井大院）正 川端 信義（福井大）

Naohito TADA, Graduate School of Fukui, Bunkyo3-9-1, Fukui-shi, fukui

Nobuyoshi KAWABATA, University of Fukui

Key Words: Water mist, Sprinkler

\section{1. 緒言}

スプリンクラーは消火設備として極めて一般的な設備であ り、室内から自動車トンネルまで大小様々な空間に適用され ている。自動車トンネルでは長大トンネルを中心に交通量の 多いトンネルに設置されており、火勢を弱め、延焼を抑え、 熱気流の遡上を抑える効果がある。しかし、放出水滴の径及 び流量についても様々であり、それぞれの空間・用途に応じ て最適な水滴径、流量があると考えられる。本研究ではスプ リンクラーの火災高温空間からの吸熱効果について、水滴径、 流量をパラメータとし、実験によって明らかにすることを目 的とする。

\section{2. 実験装置及び実験方法}

\section{1 実験装置}

実験装置の概観図を Fig.1に示す。装置の寸法は幅 5m、奥 行き $3 \mathrm{~m}$ 、高さ $3 \mathrm{~m}$ であり、鋼材で枠を組み、外壁にはトタン、 区画内部に厚さ $5 \mathrm{~mm}$ の珪酸カルシウムボードを設置し断熱 性を高めた。水噴霧の効果を定量的に評価するためには水滴 径や流量のパラメータによる整理が重要である。そこで、水 滴径や流量などの詳細データのある、スプレーイングシステ ムス社のフルコーンスプレーノズル(TG)を使用した。流量は 流量計を設置し直接計測した。水滴径は計測した流量の值を 用い、同社の性能特性図を用い決定した。また、 $\mathrm{K}$ 型熱電対 $(\Phi$ $0.1 \mathrm{~mm}$ )を用い温度計測を行った。計測点は Fig.2 に示すよう に 19 点であり、噴霧した水滴の影響を避けるため、ノズルか ら離して設置した。

\section{2 実験方法}

はじめに、ガソリンの主成分である $\mathrm{n}$-へプタン $215 \mathrm{~g}$ を燃焼 させ煙と熱を発生させる。そして、火源鎮火 30 秒後から水噴 霧を行うこととした。これは、火源燃焼中に水噴霧を行うと、 火源然焼性状等が変化し、条件を揃えることが困難になるた めである。また、装置の制約上、水噴霧開始值後は圧力、流 量が安定しないため、吸熱効果を検討する際の評価範囲は水 噴霧開始後 30 秒から、装置内の温度が周囲温度と比較して十 分高いことが確認できた水噴霧開始後 150 秒までの 120 秒間 とした。

\section{3. 区画内温度変化のモデル式}

水噴霧による吸熱効果を定量的に評価するため、燃焼終了 後の温度低下を模擬するモデル式を導出し、モデル式中の吸 熱効果を表す定数によって結果を整理した。

時刻 $\mathbf{t}(\mathrm{T}, \rho)$ 時の区画内に含まれる熱量と実験時の周囲温度 $\left(\mathrm{T}_{\mathrm{a}}, \rho\right)$ の熱量の差 $q$ は

$$
q=C_{p} V \rho\left(T-T_{a}\right)
$$

とおける。ただし、 $C p$ :定圧比熱、 $\rho$ : 密度、 $\mathrm{V}$ : 装置内容積。 微小時間 $\mathrm{dt}$ の吸熱効果は区画外部へ放熱する熱量と、水滴に よる吸熱効果の和であり、区画内温度と周囲温度の差、区画 内空気の密度に比例すると仮定する。ただし、水滴による吸 熱効果は他にも水滴が区画内を漂う平均時間や放出速度、放 出パターンにも影響を受けると考えられるがそれらの影響を まとめて $\alpha$ とおく。また、実験時の周囲温度とタンク内の水 温の差は平均 $2^{\circ} \mathrm{C}$ 程度であるため $\mathrm{T}_{\mathrm{w}}=\mathrm{T}_{\mathrm{a}}$ とした。以上より

$$
-d q=\left(h_{m}+\alpha\right) \rho^{\prime}\left(T-T_{a}\right) d t
$$

とおける。ただし、 $\mathrm{h}_{\mathrm{m}}$ :水噴霧なし時の吸熱効果を表す定数。 また、 $\mathrm{t}+\mathrm{dt}$ の熱量は

$$
q+d q=C_{p} V \rho^{\prime}\left(T+d T-T_{a}\right)
$$

とおける。モデルを等圧変化として取り扱うため

$$
\rho^{\prime}=\rho(1-\mathrm{dT} / T)
$$

とおいた。(1),(2),(3),(4)を整理し、積分すると、

$$
\left(T-T_{a}\right) / T=C \exp \left(-\left(h_{m}+\alpha\right) \mathrm{t} / \mathrm{C}_{\mathrm{p}} V\right)
$$

が得られる。Fig.3の(a)に式(5) と実験值の比較を示す。Fig.3 から燃焼終了直後の高温領域から低温領域まで、温度の減少 傾向を概ね表現できている。従って、式(5)を水噴霧時の吸熱 モデルとする。また、式(5)の定数 $\mathrm{C} 、\left(\mathrm{~h}_{\mathrm{m}}+\alpha\right)$ を最小二乗を 用い実験值に近似するような值を求めた。

水滴の吸熱効果を検討するため、水噴霧なし時の吸熱効果 を表す定数を見積もり、吸熱効果全体から引くことで水滴の 吸熱効果を得ることにした。式(5)中の水噴霧時の吸熱効果を 表す定数 $\alpha$ を 0 とおいた、式(6)を水噴霧なし時の吸熱モデル と仮定した。
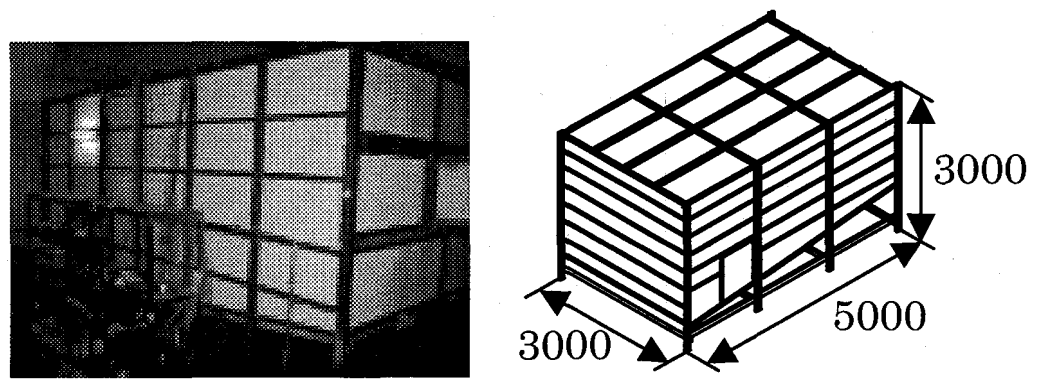

Fig1. Outline of experimental equipment

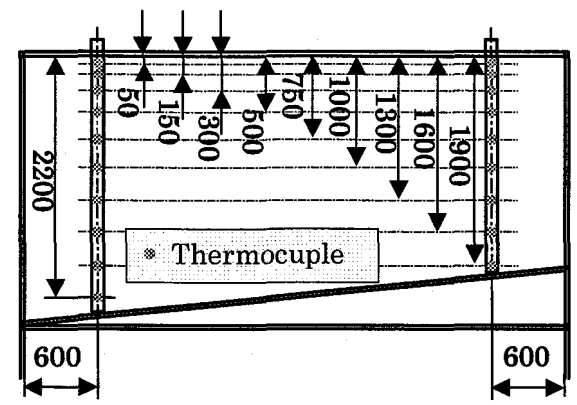

Fig.2 Thermocuple arrangement 


$$
\left(T-T_{a}\right) / T=C \exp \left(-h_{m} t / C_{p} V\right)
$$

Fig.3(b)に式(6) と実験值の比較を示す。評価範囲内において 実験值とモデル值がよく一致しており、式(6)を水噴霧なし時 のモデル式とする。さらに、式(6)を用い同樣に最小二乗を行 い $\mathrm{h}_{\mathrm{m}}$ を求めた。同様の実験を 5 ケース行い、各ケースにつ いて $\mathrm{h}_{\mathrm{m}}$ を求め、その平均を水噴霧なし時の吸熱効果を表す定

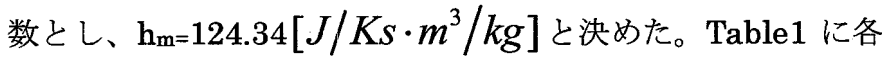
実験時の周囲温度と求めた $h_{m}$ 示す。また、Fig.3 の(a)に水噴 霧時、水噴霧なし時の結果を示すが、比較すると水噴霧によ る吸熱効果が確認できる。

Table1 Approximation result

\begin{tabular}{|c|c|c|}
\hline & $\mathrm{h}_{\mathrm{m}}\left[\mathrm{J} / \mathrm{Ks} \cdot \mathrm{m}^{3} / \mathrm{kg}\right]$ & Outside Temperature [K] \\
\hline no-water-1 & 129.7 & 304.22 \\
no-water-2 & 128 & 301.73 \\
no-water-3 & 117.4 & 294.26 \\
no-water-4 & 127 & 284.27 \\
no-water-5 & 119.6 & 282.95 \\
\hline \hline average & 124.34 & \\
\hline
\end{tabular}

\section{4. 水噴霧の吸熱効果}

ここからは、各実験ケースについて最小二乗により求めた $\alpha$ について検討する。実験データの内、明らかに異常なデータ （10ケース程度）を除き、全 102 ケースを対象とした。まず、 Fig.4 は水滴径をそれぞれ $0.2 \mathrm{~mm}, 0.3 \mathrm{~mm}$ に固定し、流量を変 化させることによる $\alpha$ の変化を示したもので、縦軸を $\alpha$ を $\mathrm{h}_{\mathrm{m}}$ で割り無次元化した值、横軸を流量をとした。Fig.5 は流量を それぞれ $0.6 \mathrm{~L} / \mathrm{min}, 0.8 \mathrm{~L} / \mathrm{min}$ に固定し、水滴径を変化させるこ とによる $\alpha$ の変化を示したもので、縦軸を $\alpha / \mathrm{h}_{\mathrm{m}}$ 、横軸を水滴 径とした。それぞれの関係について最小二乗により算出した 近似式を示す。Fig.4 から $\alpha$ は概ね流量 Q に比例することが確 認できた。また、Fig.5 から $\alpha$ は概ね水滴径の $1 / 2$ 乗に反比例 することが確認できた。そこで $\alpha$ は $\mathrm{Q} / \sqrt{\mathrm{d}}$ によって決定でき
るとし、縦軸 $\alpha / h_{m}$ 、横軸 $\mathrm{Q} / \sqrt{\mathrm{d}}$ をとり、すべての実験ケース 示したものを Fig.6に示す。Fig.6から Q/ $\sqrt{\mathrm{d}}$ が小さな領域、 つまり流量が小さく水滴径が大きな領域では $\alpha / \mathrm{h}_{\mathrm{m}}$ は $\mathrm{Q} / \sqrt{\mathrm{d}}$ に 比例することがわかる。しかし、 $\mathrm{Q} / \sqrt{\mathrm{d}}$ が大きな領域、つま り流量が大きく水滴径が小さい領域では増加の割合が減少す る傾向にあることがわかる。そこで、 $\mathrm{y}=\alpha / \mathrm{h}_{\mathrm{m}} 、 \mathrm{x}=\mathrm{Q} / \sqrt{\mathrm{d}}$ とお き、 $\mathrm{x}$ が小さい時は線形、 $\mathrm{x}$ が大きい時に一定值となる関係と して $\mathrm{y}=\mathrm{x} /(\mathrm{ax}+\mathrm{b})$ とおいた。さらに、 $\mathrm{Y}=1 / \mathrm{y}$ とし、 $\mathrm{Y}=\mathrm{a} / \mathrm{x}+\mathrm{b}$ につ いて最小二乗を行い、 $\mathrm{a} 、 \mathrm{~b}$ を決定した。その結果を Fig.7 に 示す。Fig.7 から実駼結果は概ね描かれた曲線と一致すること が確認できる。この結果より $\mathrm{Y}=1.278 / \mathrm{x}+0.3536$ で表すことが できた。つまり、 $\mathrm{y}=\mathrm{x} /(0.3536 * \mathrm{x}+1.278)$ であり、水噴霧時の吸 熱効果を表す係数 $\alpha$ と流量、水滴径との関係は

$$
\alpha / \mathrm{h}_{\mathrm{m}}=\left(Q / \sqrt{d}_{d}\right) /(0.3536 *(Q / \sqrt{d})+1.278)
$$

で表せることが分かった。

\section{5. 結言}

閉鎖、高温区画内一水噴霧を行い、吸熱効果に関して噴霧 流量および水滴径をパラメータとして検討した結果、以下の ことが明らかになった。

・水噴霧時の吸熱モデルを(5)で表すことができた。 ただし、水噴霧を行わない場合は $\alpha=0$ とする。

- 水噴霧時の吸熱効果を表す係数と流量、水滴径の関係は 式(7)で表すことができる。

参考文献

（1）川端ほか、日本火災学会研究発表会概要集、 (2004)、pp.334-337

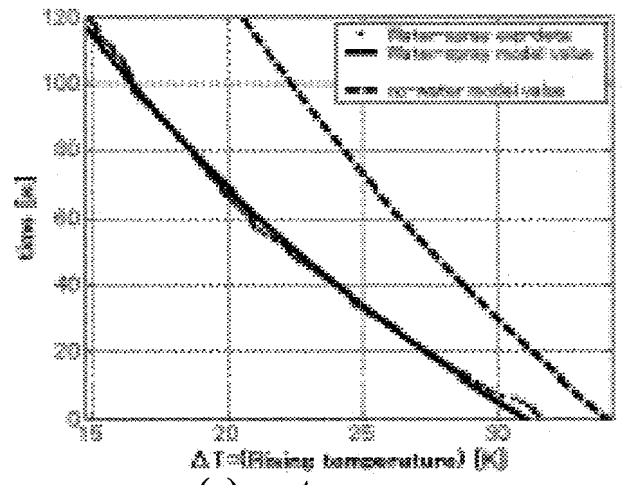

(a). water spray

Fig3. Relationship between rising temperature and time

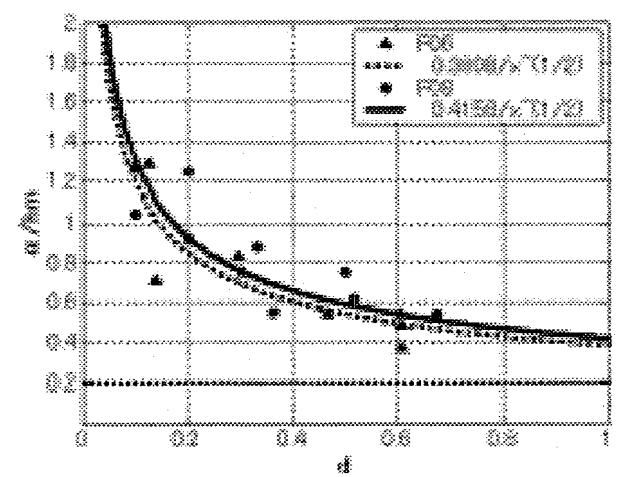

Fig.5 Relationship between $\mathrm{d}$ and $\alpha / \mathrm{h}_{\mathrm{m}}$ Fig.6 Relationship between $\mathrm{Q} \sqrt{\mathrm{d}}$ and $\alpha / \mathrm{h}_{\mathrm{m}}$

(b). no-water

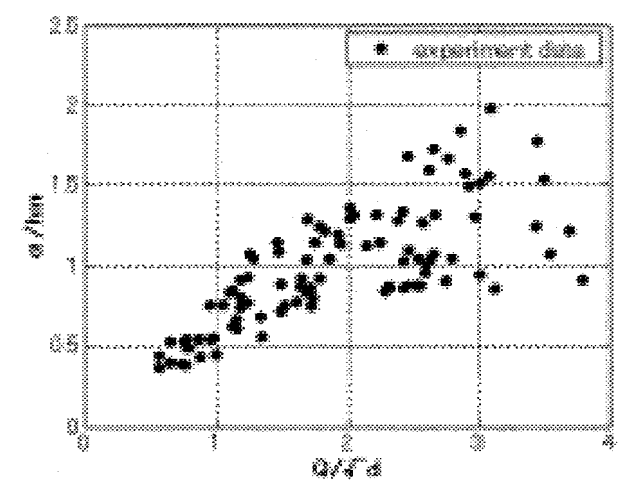

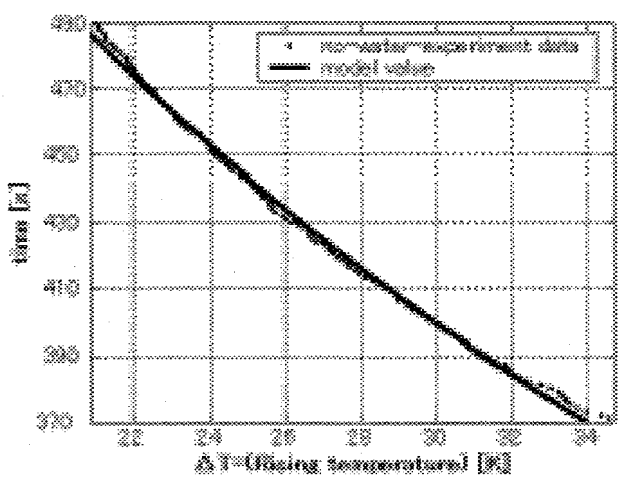

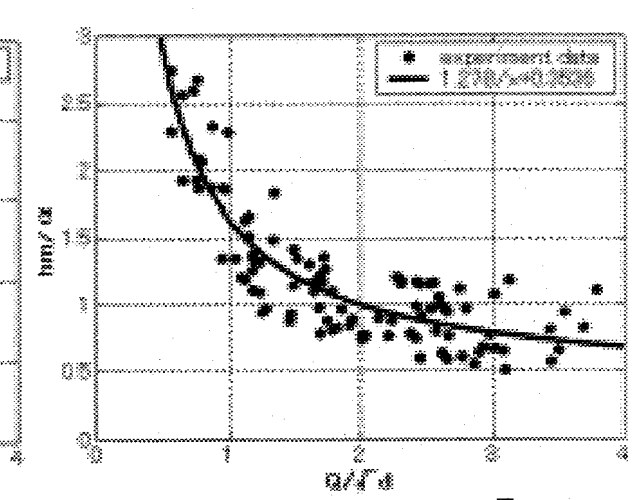

Fig.7 Relationship between $\mathrm{Q} \sqrt{\mathrm{d}}$ and $\mathrm{h}_{\mathrm{m}} / \alpha$

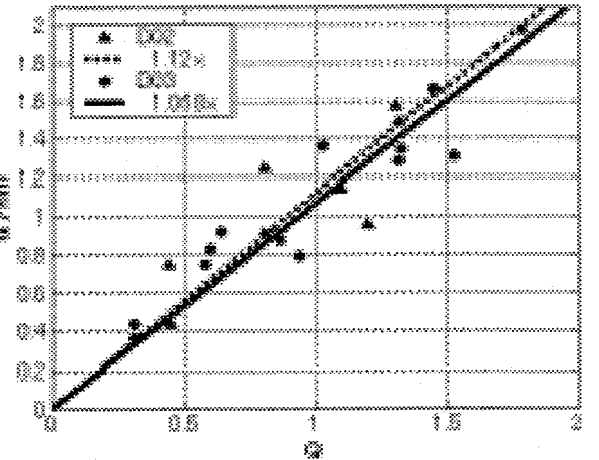

Fig.4 Relationship between $\mathrm{Q}$ and $\alpha / \mathrm{h}_{\mathrm{m}}$ 